\title{
UNDERWATER CULTURAL HERITAGE IN ASIA PACIFIC: INTRODUCTION
}

\author{
Bill Jeffery* \\ University of Guam, Unibetsedåt Guåhan, College of Liberal Arts and Social \\ Sciences, Humanities, UOG Station, Mangilao, Guam 96913, USA \\ Email: jefferyw@triton.uog.edu \\ Chihiro Nishikawa** \\ UNESCO Secretariat of the Convention on the Protection of the Underwater \\ Cultural Heritage \\ Email: c.nishikawa@unesco.org
}

Published online: 30 July 2021

To cite this article: Jeffery, B. and Nishikawa, C. 2021. Underwater cultural heritage in the Asia Pacific: Introduction. International Journal of Asia Pacific Studies 17 (2): 1-14. https://doi.org/10.21315/ijaps2021.17.2.1

To link to this article: https://doi.org/10.21315/ijaps2021.17.2.1

This 2021 themed issue of the International Journal of Asia Pacific Studies explores a diverse heritage of humanity found throughout the Asia-Pacific region - its "Underwater Cultural Heritage" (UCH). The study of UCH dates from the 1960s through the pioneering effort of Dr. George Bass and his work in the Mediterranean. Sadly Dr. Bass passed away in March 2021, but his legacy lives on in all of us who work in this field and in the community who benefit from the knowledge that he inspired to be revealed.

The Asia-Pacific region contains some of the oldest connections humans have with the sea, through species from the homo genus crossing over to the island of Flores in Indonesia between one to two million years ago, from either colonisation/seafaring, or accidental, natural migration (Dunne 2017; Ruxton and Wilkinson 2012). In Oceania, seafarers navigated by the stars, watched the path of migrating birds and understood weather and wave patterns. They developed an intimate knowledge of the ocean and sailed the breadth of the world's largest ocean in outrigger and double-hull canoes in planned explorations, thousands of years before Western explorers reached the region (D'Arcy 2006). When foreigners saw the traditional indigenous 
canoes in Guam, they marvelled at their agility and speed (Cunningham 1992). This connection with the coast and sea has led to traditional indigenous people living in balance and harmony with the islands' environment and spiritual world, utilising traditional ecological knowledge (TEK) (also called traditional ecological science, TES) which carries through to today and can be seen in their intangible cultural heritage (living heritage). Their world did not stop at the edge of their land but included the sea as facilitating connections to other islanders - it was an integral part of their physical and spiritual world (Hau'ofa 1994).

The Asia-Pacific region has developed into one of the most significant in terms of world trade. Beginning with an extensive intra-regional trade network that encompassed great maritime powers such as the Srivijaya thalassocracy from Sumatra, Java and the Malay Archipelago, this grew into broader inter-regional trade that became known as the Maritime Silk Road. This trade connected China, Japan, South Korea, Taiwan, Vietnam, Cambodia, Philippines, Thailand, Indonesia, Brunei, Malaysia, India, Sri Lanka, with countries in the Middle East, Africa and Europe. Western nations found their way into the Indian and Pacific Oceans hundreds of years later and were astonished and dwarfed by the much larger, well-built vessels of Southeast Asia (Manguin 1980: 267). The Asia-Pacific region encompasses shipwrecks, port cities and diverse societies involved in this trade. Some of the shipwrecks contain 1,000 years old highly sought-after Chinese porcelain. This contemporary "competition" for porcelain from archaeologists, who are researching and preserving this material in context with all of the shipwreck site as public heritage and commercial salvagers who regard it as riches for themselves and investors, was a catalyst for the development of the UNESCO (United Nations Educational, Scientific and Cultural Organization) Convention on the Protection of Underwater Cultural Heritage (2001 Convention).

In addition to acknowledging this significant human connection with the coast and sea that characterises the Asia-Pacific region, the articles in this themed issue are timely given that the decade of 2021-2030 has been designated by the UN (United Nations) as the Decade of Ocean Science for Sustainable Development. It is an initiative where UCH and the associated TEK/TES in the Asia-Pacific region can play an important role (UNESCO 2021a). The other issue of note is that it has also been 20 years since the wording for the 2001 Convention was adopted at the UNESCO General Conference and which has now been ratified by 68 countries (UNESCO 2021b). 
Currently many countries in Asia Pacific play an active role in researching and preserving $\mathrm{UCH}$. These have not been recent interests; some date back 40 to 50 years. They are not all at the same stage of development: South Korea for instance has a National Research Institute of Maritime Cultural Heritage that combines the work of 146 people with a budget of USD19.5 million as at 2019 and two superb maritime museums; the Philippines has 22 staff, together with exhibitions at a number of museums including the National Museum of the Philippines. Thailand has a staff of 30 , with resources (but with a reduced budget) and exhibitions at the National Maritime Museum including a virtual Maritime Museum. In Oceania, while projects have been implemented in a number of countries and territories, and maritime archaeological material can be found in a number of museums (including New Zealand, French Polynesia, Fiji, Solomon Islands, Mariana Islands, the Republic of the Marshall islands and the Federated States of Micronesia) and while there is legislation to protect $\mathrm{UCH}$ in many places, their activities tend to be of a piecemeal nature and not through an ongoing programme. The United States of America (USA) state of Hawaii in Polynesia does have an active UCH programme through the USA National Oceanic and Atmospheric Administration's Office of National Marine Sanctuaries. An active country in UCH management in Oceania is Australia, which has well-resourced and organised federal and state programmes, which began in the 1960s in western Australia investigating 17th century Dutch shipwrecks and continues today through a broader UCH approach. The Australian national and state government officials implement programme activities supported by effective engagement of community scuba divers and in collaboration with a number of universities, several national, state and local museums and legislative frameworks.

While the definition of UCH is broad and includes "all traces of human existence having a cultural, historical or archaeological character which have been partially or totally under water, periodically or continuously, for at least 100 years", much of the focus for maritime archaeology throughout the region is still on shipwrecks (UNESCO 2021b). This can be seen in the number of projects implemented in China, Japan, South Korea, Philippines and Thailand and where locally built and used ships are increasing focuses. It is worth noting that the term "shipwreck" is not to be found in the 2001 Convention, thus providing a more holistic approach to what is underwater cultural heritage and in part helping to diminish the neo-colonial focus that came from investigating the 16th to 20th century colonial-era and war shipwrecks. Shipwrecks are also just a part of the bigger picture of trade, 
migration, navigation, settlement, commerce, ports and harbours, maritime industry, battles at sea and wars. Should these additional sites be part of the research and management of underwater cultural heritage? A number of maritime archaeology projects implemented in the region do include this broad heritage context.

Through the collaboration of universities in Japan, Philippines, South Korea, Micronesia and Poland, traditional indigenous UCH and living heritage associated with the sea is being developed as a significant area of archaeological and heritage research, preservation and maintenance of traditional cultural values (ICOMOS [International Council of Monuments and Sites] 2021: 96-99). Using a cultural landscape/seascape approach, an aim is to connect tangible cultural heritage and living heritage with the marine ecology to illuminate what people were thinking and doing over time within this environment - such as utilising TEK/TES — and incorporating this knowledge with 21 st century science to benefit the UN's Decade of Ocean Science programme. This approach in general can include cultural practices, sacred and spiritual associations, customs, navigation, boat building, lore, exchange systems, songs and dancing, with objects and sites that are a primary focus for people and their heritage in the Asia-Pacific region. It is this holistic approach that can reveal the rich and vibrant maritime cultural identity of people in this region.

This issue of IJAPS contains six Asia Pacific UCH-related articles that encompass research topics, policy and management approaches and community engagement and thus provide a window into the activities of past and contemporary maritime societies. It includes a diverse range of authors from Japan, Philippines, Thailand, Hong Kong, Australia and the USA, being a good representation of the many practitioners active in maritime archaeology in Asia Pacific. It is worth highlighting that seven of the authors are female and three are male, in a field that has in the past been dominated by men and their approaches to the interpretation of $\mathrm{UCH}$.

The series of articles commences with the article "Underwater Cultural Heritage in Asia Pacific and the UNESCO Convention on the Protection of the Underwater Cultural Heritage" - by Chihiro Nishikawa, who needs to be acknowledged and thanked for instigating this series of themed articles on UCH. Nishikawa's article pays particular attention to the Southeast Asia area where a number of important shipwrecks have been commercially exploited and the ratification of the UNESCO convention remains a big challenge. Importantly, the article outlines the benefits 
for countries in this area in ratifying the UNESCO Convention and in international collaboration, using examples from elsewhere on how this is being achieved. In the Asia-Pacific region, only four of the 44 member states of UNESCO have ratified the UNESCO convention: Cambodia, Iran, the Federated States of Micronesia (FSM) and Niue, a process in which the FSM acknowledged was an important step in supporting their shipwreck diving tourism industry. To assist in the development of a proactive approach in implementing maritime archaeology programmes, UNESCO has taken certain initiatives such as implementing capacity building programmes for local people, regional meetings, publications and ASEAN (Association of Southeast Asian Nations) meetings. However, the lack of effective measures and funding in particular are acknowledged as restricting the aims of the 2001 Convention and some countries chose to work with commercial salvage companies and share the proceeds of this work. A number of collaborative programmes are outlined, such as the United Nations Decade of Ocean Science for Sustainable Development and the 17 Sustainable Development Goals; these initiatives are designed to "make the world a better place", and in particular with the ocean where $\mathrm{UCH}$ can play an important role.

In the Philippines, Kristine Kate A. Lim, Bobby C. Orillaneda and Catherine P. King investigated "People and the Sea: A Values Perspective in the Conservation Management of Maritime Heritage in the Philippines". Shipwreck discoveries and investigations began in the Philippines in 1967, when the National Museum of the Philippines collaborated with other government agencies and private groups, but it was not until 1979 that an Underwater Archaeology Unit with National Museum of the Philippines was created. Since then, many initiatives and activities have taken place and today, the renamed unit, the Maritime and Underwater Cultural Heritage Division, has a staff of 22. This has been complemented with the development of post-graduate and Doctor of Philosophy (PhD) programmes in Archaeology and courses in underwater archaeology at the University of the Philippines-Diliman. The authors offer a comprehensive assessment and synthesis of numerous issues, including the nature of the Philippine $\mathrm{UCH}$, past underwater archaeology projects, legislation, and management arrangements in considering and developing a strategic approach to "sustainable and culturally responsive UCH protection" in the Philippines. They conceptualise the many different permutations of the "value" of $\mathrm{UCH}$ and regard a "values-led and people-centred approach" in the Philippine 
$\mathrm{UCH}$ - as warranting further examination. The authors also consider intangible cultural heritage and the need to "think beyond materialty" as an important focus for the Philippine UCH programme.

The discovery of a second sewn-plank boat (the first being the Belitung of Tang shipwreck found in Indonesia) in context with UCH management in Thailand is the topic for the article, "Management of the Phanom-Surin Archaeological Site in Thailand: Concept, Policies and Practices" by Abhirada Komoot. The Phanom-Surin is a sewn-plank vessel, which has been dated to the 9th century CE and is located in a mangrove swamp, which has kept it well-preserved, southwest of Bangkok. It is the only sewn-plank built vessel, a construction method used in the western Indian Ocean currently available for study anywhere in the world. The author places the investigation of the Phanom-Surin in context with the Thailand government's approach to the management of cultural heritage, where there is well-established philosophy in regard to build heritage management, but to a lesser extent, archaeological heritage. Nevertheless, the Phanom-Surin is regarded as an important site. It includes the remains of a vessel built of Southeast Asian material, using western Indian Ocean construction methods and containing Thai, Chinese and possibly Persian ceramics. In addition to the Phanom-Surin shipwreck being a $\mathrm{PhD}$ topic for the author, it has attracted other academic interest and is a focus for considerable international collaboration. Of particular concern for the author is how the vessel will be managed in the future, whether it is through in situ management where the geographical context and significance are acknowledged as a well-accepted international approach, or through archaeological recording, removal and public exhibition.

In Hong Kong, the work of a community group, the Hong Kong Underwater Heritage Group (HKUHG), and the Hong Kong Maritime Museum is explored by Bill Jeffery and Joyce Ho-ching Kam in their article, "Revealing a Maritime Cultural Landscape of Hong Kong: The Sai Kung Case Study". The Hong Kong Special Administrative Region that comprises the island of Hong Kong, 250 other islands, and sections of the adjacent Chinese mainland, contains evidence of human occupation dating back to 6,000 to 7,000 years. The article provides an overview of this archaeological evidence as well as Hong Kong's recent maritime history and a more detailed archaeological investigation of the human interaction with the coast and sea in an eastern district of islands and mainland coastline, known as Sai Kung. This district contains Neolithic sites, rock carvings, temples, forts and shipwrecks. In a number of maritime archaeological projects implemented 
by HKUHG from 2014 to 2017, a further understanding of the use of the region by traders and fisher folk was advanced. The authors supplemented this tangible material with the intangible cultural heritage to provide a richer, more holistic appreciation of the maritime cultural landscape of Sai Kung.

The major focus for the penultimate paper is primarily Oceania and the investigation of $\mathrm{UCH}$ in this region has been through a sampling of three temporal themes by Bill Jeffery, Jennifer F. McKinnon and Hans Van Tilburg, titled "Underwater Cultural Heritage in the Pacific: Themes and Future Directions". This is a vast region and it is characterised by people living on islands in the sea and containing many cultural, sacred and spiritual ties for people, called living heritage. The sea has different connotations to islanders compared to folk from continental land masses. The sea connects islands and islanders rather than separating continents and those living there. Islanders lived in the sea, are fed by what is in the sea and travelled the sea, developing many exchange systems, including tribute and trade with other islanders. It is a fundamental part of their culture and society. Through investigating the three themes which cover 3,500 years of the region's human history, the authors connect the themes through living heritage and the legacies of the foreign interventions. This includes the living heritage of traditional indigenous people and their indigenous UCH sites, the legacy of the global connections of the Manila Galleon Trade, and the legacy of the modern warfare of World War II. The article reveals many aspects of the cultural identity of people living in the region, which the authors recommend as the most relevant motive and direction for moving forward with a UCH programme, given this would be aimed at and benefit people from within the region.

Last but certainly not least is the important discussion about community and scholarly engagement and awareness raising throughout Asia Pacific, by Michelle M. Damian in "A Retrospective on the AsiaPacific Regional Conference on Underwater Cultural Heritage". The author takes a critical look at this regional networking event, called APCONF (Asia-Pacific Regional Conference on Underwater Cultural Heritage), which has been held in the Philippines in 2011, Hawaii in 2014, and then Hong Kong in 2017. It was also planned for Taiwan in 2020, but was postponed until November 2021 because of the COVID-19 pandemic. The conference organisers, all of whom are volunteers, intended the conference to be alternatively shared from a venue in Asia, then the Pacific, and for the programme committee members to be drawn from across the region. 
Attracting on average 127 delegates from 30 nations for each of the three events held so far, the conference has developed into a significant forum for sharing knowledge about maritime archaeology projects and issues in Asia Pacific not just for scholars, practitioners and those working in the field and allied professions, but also for members of public. It has also attracted interest and sponsorship from various government, non-government offices and private businesses. An important focus for the conference programme and venue committees has been in seeking funding for delegates, particularly for those from developing countries where costs for travel can be prohibitive for many individuals and organisations. The APCONF committees have been reasonably successful in this endeavour.

Damian's article provides excellent background on many $\mathrm{UCH}$ research and preservation activities, in addition to indicating some trends for the future of maritime archaeology in the Asia-Pacific region. The APCONF was developed in 2011 to allow for a "free exchange of information" (Damian, this issue), and to:

Address management and protection strategies of underwater cultural heritage in Asia and the countries of the Indian and Pacific Oceans in the 21st century, facilitate regional cooperation through the development of academic, non-governmental organisations (NGO) and governmental networks in the Asia-Pacific region and provide a forum for discussion of technical and ethical issues related to underwater cultural heritage and underwater archaeology. (APCONF 2021)

While 10 years later this is still an aim for APCONF and are important issues for maritime archaeology programmes in the region, the conference has developed a more holistic and socio-cultural inclusive dimension, which is evident in the conference themes and a reflection of the dynamic programmes and projects being implemented. This can be seen in the theme for the Hong Kong conference, "The Maritime Cultural Landscapes and Seascapes of Asia-Pacific: Voyaging, Migration, Colonisation, Trade and Cross-Cultural Contacts" in addition to the theme for Taiwan in 2020/2021, "The Maritime Cultural Landscape of the Austronesian Diaspora". The programmes implemented in South Korea, Philippines, Australia and China, for instance are government funded programmes, implementing many activities such as field studies, research, artefact and site conservation, in situ preservation and interpretation and museum exhibitions. The in situ projects include some amazing sites, such as the Baiheliang Underwater 
Museum in Fuling, China, where 1,200 year old inscriptions and carvings on the riverbed that recorded changes in the level of the Yangtze and are now 40 metres underwater through the construction of the Three Gorges Dam. It is possible to take an escalator down to view a section of these inscriptions, which include fish, a crane figure (the area is also referred to as White Crane Ridge, after this carving) and various styles of calligraphy used in the inscriptions referred to as "an outstanding demonstration of Chinese culture" (Yangtze River Cruises 2021). In Bikini Atoll, Marshall Islands and in Chuuk Lagoon, FSM, two regions in Oceania contain arguably the best in situ World War II shipwreck diving in the world. In 2017, the Japanese government provided USD3 million for a three year programme of investigating and implementing countermeasures to the oil leak from the shipwrecks in Chuuk Lagoon (UNESCO 2018). Illustrating the diversity of UCH in Asia Pacific is Nan Madol, located in Pohnpei, FSM. Now a World Heritage site, it was the "Ceremonial Centre of Eastern Micronesia" from about 800 years ago and consists of 90 artificial islets built of columnar basalt and coral boulders spread over an area of $1.5 \mathrm{~km} \times 0.8 \mathrm{~km}$ in the intertidal zone (NACH [National Archives, Culture and Historic Preservation] 2015). "Nan Madol is the most expansive and outstanding example of an emerging state-level centre throughout the whole of Oceania" (NACH 2015: 71).

In addition to in situ projects and activities, the region has developed many vibrant and popular museums, incorporating seafaring and maritime archaeology exhibitions that interpret the results of many years of field work and thousands of years of maritime history. They include the relatively well-funded national and state museums to the often less well-funded but important volunteer managed provincial and district museums. Some notable examples are the Museum of Tropical Queensland's exhibition of the HMS Pandora shipwreck, comprising a range of 18th century ethnographic material from Oceania, which was collected by the crew of the vessel while searching for the HMS Bounty; the South Korean National Museum, holding the largest collection of Chinese Yuan dynasty celadon through the excavation of the Sinan shipwreck; and the Guangdong Maritime Silk Road Museum, exhibiting the excavation of the Song dynasty Nanhai No. 1 shipwreck and comprising the ship remains and 100,000 pieces of porcelain and gold, copper and stone artefacts destined for trade in the Indian Ocean. There are also many examples of traditional craft being built and used in the region, keeping alive traditional practices and with many craft located in various museums, such as the last of the Fijian Drua, the ocean going double-hull 
canoe, the Ratu Finau Tui Nayau, located at the Fiji Museum; and a fullscale replica of a ship, the Samudra Raksa, based on a Borobudur temple relief in Java, Indonesia, and which recreated the cinnamon trade route from Indonesia to West Africa. In Jibei Island, Penghu, Taiwan, a whole village museum is devoted to the living heritage and tangible cultural heritage related to weir fishing, where visitors gain a holistic appreciation-social, cultural, spiritual and environmental — of using the stone-wall tidal fish weirs - and participate in live in school programmes to help build fish weirs. The living heritage of navigation (wayfinding) using traditional canoes in Oceania is being revived, inspired in particular by one man, Mau Piailug (Papa Mau), a Micronesian navigator from Satawal, FSM and who has been acknowledged with his name emblazoned on a Matson ship servicing the USA and the Mariana Islands (Pang 2016).

There are many other examples of such important outreach/raising community awareness/community engagement activities throughout the region. The awareness of the importance of the Asia Pacific community has been raised through the implementation of a number of training - and capacity building programmes in various countries, including-Vietnam, Taiwan, Hong Kong, the Mariana Islands and most notably the maritime archaeology foundation courses in Thailand conducted by UNESCO from 2009 to 2011 (Favis 2011). These programmes have been successful in engaging with many young men and women from within the region to provide the skills required to conduct projects that matter to them and their community. Many have gone on to pursue Masters and $\mathrm{PhD}$ programmes at Flinders University in Adelaide, South Australia. As can be seen in Japan, Thailand, the Philippines and Indonesia, graduates have moved into academic institutions and government agencies to engage with partners and people from within the region to implement a number of initiatives.

There is certainly no lack of enthusiasm and knowledge in researching, preserving and interpreting maritime and underwater cultural heritage and to realise the cultural identity inherent in this important cultural heritage from many of the region's public maritime archaeologists. However support, particularly political and financial support in some countries, is sparse, which can result in short-sighted options and detrimental consequences to this cultural heritage. The need for political and financial support is crucial in moving forward. Political support in ratifying the 2001 Convention, enacting effective domestic legalisation and providing adequate finances to support a proactive programme, including awareness raising activities, is required. 
Legislation on its own is not the answer; it must be complemented with a proactive and holistic programme, encompassing effective law enforcement and engaging with the community. In many cases, the community can be directing what maritime archaeologists implement - community maritime archaeology. It is well-known that having the community engaged is a most important factor in cultural heritage protection and management, and if the community lacks a decent living or is barely able to survive, sites will suffer, particularly $\mathrm{UCH}$ where there is the potential to earn considerable money from commercial exploitation. This has been and is the case in parts of Asia Pacific. As a consequence and through the lack of political and financial support for public maritime archaeology projects, some have called for collaboration with commercial salvage companies where they make money from acquiring and selling artefacts as part of an agreement with governments (Dissanayake 2020: 5). It is worth noting that at a conference in Singapore in 2011 centred on the Belitung shipwreck, in which Bill Jeffery attended, and when this issue was discussed, the comment from a commercial salvage operator was that they could not earn their money through a contractor's fee, as is the case with hundreds of consultant archaeologists. It was said to be too difficult, particularly as it was acknowledged that the investors want artefacts (Tan 2012).

Further discussion on the politics pertinent to Asia Pacific UCH is beyond the scope of this introduction to this excellent issue. But some remarks on the funding required in maritime archaeology and the preservation of $\mathrm{UCH}$ are made. For countries like Indonesia and the Philippines with thousands of islands, it can be an expensive and nigh impossible task to employ the necessary personnel to research, survey and preserve $\mathrm{UCH}$ and this is where good community engagement and initiatives that support the community are important. Other creative avenues for funding need to be considered. An initiative that is being used to financially support countries to not log their rainforests, in the context of protecting their natural resources and supporting traditional Indigenous people, could indicate a path for $\mathrm{UCH}$ financial assistance. The preservation of rainforests has a benefit for all of humanity and the Rainforest Foundation Norway has a number of partners in supporting preservation efforts in developing countries including Indonesia, Papua New Guinea, Brazil, Peru and Columbia (Rainforest Foundation Norway 2021). In supporting developing countries to preserve UCH, which the 2001 UNESCO Convention cite as "an integral part of the cultural heritage of humanity" (UNESCO 2021b), a similar creative and collaborative approach could be 
implemented by developed countries such as China, USA, Japan, UK, Spain, Netherlands and Australia - countries whose cultural heritage now lay on the seabed throughout Asia Pacific and where the developing countries are in dire need of resources to care for them.

UCH in Asia Pacific is a diverse and highly significant heritage and many important initiatives in documenting and preserving this heritage have been conducted since the 1970s. Yet few countries in the region have ratified the 2001 Convention. Why? In Latin America and the Caribbean region, which has suffered from similar commercial exploitation and destruction of its $\mathrm{UCH}$, as has Southeast Asia, 20 countries have ratified the 2001 Convention and developed an effective collaborative approach to the protection of UCH, financially supported by Spain and the Netherlands (UNESCO 2015). Different regions and different countries in the world have their own social, cultural, political, economic and geographical identities and complexities and it is not always instructive to compare, but what the comparison does highlight in this case is that regional cooperation is important, together with support from interested parties.

When the World Heritage Committee found certain regions had few world heritage sites, they instituted a global strategy for each of the different regions, resulting in 39 new countries ratifying the convention and a $400 \%$ increase in submissions of tentative lists (UNESCO 2021c). It is time for a similar approach to be instituted for UCH in support of the work of the many passionate public maritime archaeologists and heritage practitioners in Asia Pacific working toward revealing the maritime cultural identity of the region and preserving tangible cultural heritage and living heritage for the benefit of their community and humanity as a whole.

\section{NOTES}

* Bill Jeffery is an Associate Professor, Anthropology, University of Guam and holds a $\mathrm{PhD}$ from James Cook University, Townsville, Australia. His primary interest is maritime archaeology, which he commenced in Australia before going on to work with the Federated States of Micronesia National Historic Preservation Office and in Hong Kong. His interests are in researching traditional indigenous material culture and living heritage particularly in Oceania, revealing multi-vocality perspectives of underwater cultural heritage, developing community maritime archaeology and highlighting how maritime cultural landscapes can reflect maritime cultural identities.

** Chihiro Nishikawa is a Programme Specialist in the Secretariat of the Convention on the Protection of the Underwater Cultural Heritage (the 2001 Convention) at UNESCO. She holds a Bachelor's degree (BA) in Law from Doshisha University (Japan), and 
Master's degrees (MA) in International Relations from Ritsumeikan University (Japan) and also in Heritage and Interpretation from the University of Leicester (UK). Joining UNESCO in 1994, she has extensive professional experience in international cooperation, heritage protection and management. Positioned in the Secretariat of the 2001 UNESCO Convention since 2018, she has been in charge of the promotion and implementation of the 2001 Convention in Asia Pacific and the Arab States.

\section{REFERENCES}

APCONF (Asia-Pacific Regional Conference on Underwater Cultural Heritage). 2021. The Asia-Pacific regional conference on underwater cultural heritage. https://www.apconf.org/ (accessed 8 April 2021).

Cunningham, L. J. 1992. Ancient Chamorro society. Honolulu: Bess Press.

D'Arcy, P. 2006. The people of the sea: Environment, identity and history of Oceania. Honolulu: University of Hawaii Press.

Dissanayake, S. 2020. The wreck detectives. BBC News. https://www.bbc.co.uk/news/ resources/idt-4b0483fb-376b-4fa2-9ebf-2d38959d55bf (accessed 18 April 2021).

Dunne, D. 2017. Indonesia's Flores "hobbits" may be the earliest human species to have left Africa 1.75 million years ago. Mail Online, 21 April. https://www.dailymail .co.uk/sciencetech/article-4429596/Indonesian-hobbits-early-form-human.html (accessed 18 April 2021).

Favis, R. 2011. UNESCO regional capacity building programme on safeguarding the underwater cultural heritage of Asia and the Pacific. The MUA collection. http://www.themua.org/collections/items/show/1213 (accessed 18 April 2021).

Hau'ofa, E. 1994. Our sea of islands. The Contemporary Pacific 6 (1): 148-161. https://scholarspace.manoa.hawaii.edu/bitstream/handle/10125/12960/v6n1-148 -161-dialogue.pdf (accessed online 18 April 2021).

ICOMOS (International Council of Monuments and Sites). 2021. Heritage and the sustainable development goals: Policy guidance for heritage and development actors. Paris: ICOMOS. https://www.icomos.org/images/DOCUMENTS/ Secretariat/2021/SDG/ICOMOS_SDGs_Policy_Guidance_2021.pdf (accessed 16 April 2021).

Manguin, P. Y. 1980. The Southeast Asian ship: An historical approach. Journal of Southeast Asian Studies 11 (2): 266-276. https://doi.org/10.1017/S00224634 0000446X

NACH (National Archives, Culture and Historic Preservation). 2015. Nan Madol: Ceremonial center of Eastern Micronesia. Nomination by the Federated States of Micronesia for inscription on the World Heritage List, January. http://whc.unesco. org/en/list/1503/documents/ (accessed 18 April, 2021).

Pang, N. 2016. Vessel named after master navigator. The Guam Daily Post, 17 September. https://www.postguam.com/news/local/vessel-named-after-masternavigator/article_afa55e22-7bf3-11e6-85a2-4f0697e40a33.html\#: :text=Pius\%20 $\% 22 \mathrm{Mau} \% 22 \% 20$ Piailug\%2C\%20fondly,regular\%20routes $\% 20$ through $\% 20$ the\%20region (accessed 17 April 2021). 
Rainforest Foundation Norway. 2021. Only one third is still intact: State of the Tropical Rainforest, 9 March. https://www.regnskog.no/en/ (accessed 18 April 2021).

Ruxton, G. D. and Wilkinson, D. M. 2012. Population trajectories for accidental versus planned colonisation of islands. Journal of Human Evolution 63 (3): 507-511. https://doi.org/10.1016/j.jhevol.2012.05.013

Tan, H. 2012. Maritime archaeology in Southeast Asia: Innovation and adaptation. Singapore: Asian Civilisations Museum.

UNESCO(United Nations Educational, Scientific and Cultural Organization). 2012. Training manual for the UNESCO foundation course on the protection and management of underwater cultural heritage in Asia and the Pacific. https://unesdoc.unesco .org/ark:/48223/pf0000217234 (accessed 1 April 2021).

2015. Underwater cultural heritage in Latin America and the Carribean. Culture and Development 13: 16-21. https://unesdoc.unesco.org/ark:/48223/pf0000232894 _eng (accessed 20 April 2021)

. 2018. National consultation on the underwater cultural heritage held in Chuuk. http://www.unesco.org/new/en/member-states/single-view/news/national _consultation_on_the_underwater_cultural_heritage_sa/ (accessed 20 April 2021). . 2021a. United Nations decade of ocean science for sustainable development (2021-2030). https://en.unesco.org/ocean-decade (accessed 14 March 2021). 2021b. Underwater cultural heritage. http://www.unesco.org/new/en/culture/ themes/underwater-cultural-heritage/ (accessed 1 April 2021).

2021c. Global strategy. https://whc.unesco.org/en/globalstrategy/ (accessed 18 April 2021).

Yangtze River Cruises. 2021. Baiheliang Underwater Museum: World first underwater museum. https://www.yangtze-river-cruises.com/attractions/baiheliang-underwater -museum.html (accessed 15 April 2021). 